\section{Measuring heavy metal content in bone using portable X-ray fluorescence}

\author{
Nicole C. Little, ${ }^{1}$ Victoria Florey, ${ }^{1}$ \\ Irma Molina, ' Douglas W. Owsley, \\ Robert J. Speakman ${ }^{3}$
}

1Smithsonian Museum Conservation Institute, Suitland, MD; ${ }^{2}$ Division of Physical Anthropology, Smithsonian National Museum of Natural History, Washington, DC; ${ }^{3}$ Center for Applied Isotope Studies, The University of Georgia, Athens, GA, USA

\section{Abstract}

The ability of inorganic-based analytical chemistry techniques to quantify trace amounts of heavy metals in skeletal remains has been integral for understanding health and social status in human populations. Low detection limits and the sensitivity of inductively coupled plasma-mass spectrometry (ICP-MS) and other techniques to most elements on the periodic table are ideally suited for the quantification of lead $(\mathrm{Pb})$ and other heavy metals in bone. However, the time required for sample preparation and analysis, expense, destructive analytical process, and availability of instrumentation often limit researchers' ability to utilise these techniques for archaeological applications. This paper explores the use of portable X-ray fluorescence (XRF) instrumentation for heavy metal analysis of bone as an alternative to more traditional analytical techniques. XRF has been shown to be an extremely useful tool for archaeologists seeking to conduct quantitative analyses of cultural materials such as obsidian and metals. However, little research has been undertaken to assess the usefulness of portable XRF for measuring heavy metals found in low concentrations in archaeological bone. This paper compares data derived from ICP-MS and portable XRF analyses of bone. Results demonstrate that XRF analyses of bone are problematic due to diagenesis and variability of $\mathrm{Pb}$ content in bone.

\section{Introduction}

Childhood and adult exposure to lead $(\mathrm{Pb})$ in colonial American populations historically has been attributed to the prominence of leadglazed pottery in households (Hume, 1969). Other sources include the use of pewter vessels and spoons, consumption of contaminated wines and distilled spirits, and the handling and making of bullets. Lead is a toxic poison, and ingestion by children can result in mental retardation and elevated mortality rates (Neeldman, 1992), along with a variety of serious pathological conditions in adults including bowel impactions and neurological impairment. Because human bone accumulates lead throughout an individual's lifetime, the amount of lead in bone can typically account for 70-90\% of an individual's lifetime lead burden (Bellis $e t$ al., 2006). In order to better understand the extent of lead poisoning in Chesapeake region historic period populations, Smithsonian researchers have been working to establish a database for American populations from early Colonial times to the near-present that includes the trace metal content of $\mathrm{Pb}$ and other heavy metals (e.g. As and $\mathrm{Hg}$ ) in human bone. Because wealthier families had significantly greater access to lead-glazed pottery and pewter, as well as potential pharmaceuticals containing mercury and arsenic, the quantification of heavy metals in human remains has the added benefit of providing a window into the health and economic status of these populations (Aufderheide et al., 1981, 1988). Traditionally, researchers have used various methods for the quantification of lead in bone, including instrumental neutron activation analysis (INAA), Xray fluorescence (XRF), atomic absorption spectroscopy (AAS), and inductively coupled plasmamass spectrometry (ICP-MS) (Aras et al., 1999; Bellis et al., 2006; Farnum et al., 1995; Hoppin et al., 1995). Low detection limits and sensitivity of ICP-MS to most elements on the periodic table make this technique ideally suited for the quantification of $\mathrm{Pb}$ and other heavy metals in bone (Speakman et al., 2005, 2007). However, the time required for sample preparation and analysis, instrumentation expense and availability generally limits the use of this technique for archaeological applications. In addition, destructive sampling of human remains is oftentimes not possible due to restrictions imposed by museums and/or cultural groups. In an attempt to identify an alternative, inexpensive, and non-invasive analytical approach, we examined portable-XRF (PXRF) for heavy metal analysis of bone. XRF has been shown to be an extremely useful tool for archaeologists doing quantitative analysis of cultural materials such as obsidian and metals. However, little research has been undertaken to optimise portable XRF for the measurement of heavy metals in bone and/or assess data generated from such endeavors. This study focuses on the calibration of portable XRF instrumentation for the quantification of lead in bone followed by the comparison of XRF data to ICP-MS measurements for the same 25 individuals.
Correspondence: Robert J. Speakman, Center for Applied Isotope Studies, The University of Georgia, 120 Riverbend Rd, Athens, 30602 GA, USA.

Tel. +1.301.238.1243 - Fax: +1.301.238.3709.

E-mail: archsci@uga.edu

Key words: portable XRF, LA-ICP-MS, human bone, lead.

Acknowledgments: the authors thank the Bureau of Reclamation, especially Lisa Croft, Deputy Area Manager, and archaeologists Mark Hungerford and Jeffrey Hanson, and Rev. Larry Madden, Holy Trinity Catholic Church, for access to the Fort Craig and Trinity Church bone samples.

Citation: Little NC, Florey V, Molina I, Owsley DW, Speakman RJ, 2014. Measuring heavy metal content in bone using portable X-ray fluorescence. In: RH Tykot (ed.), Proceedings of the $38^{\text {th }}$ International Symposium on Archaeometry - May $10^{\text {th }}-14^{\text {th }} 2010$, Tampa, Florida. Open Journal of Archaeometry 2:5257.

Presented at the $38^{\text {th }}$ International Symposium on Archaeometry - May $10^{\text {th }}-14^{\text {th }} 2010$, Tampa, Florida.

This work is licensed under a Creative Commons Attribution 3.0 License (by-nc 3.0).

(C) Copyright N.C. Little et al., 2014

Licensee PAGEPress, Italy

Open Journal of Archaeometry 2014; 2:5257

doi:10.4081/arc.2014.5257

\section{Materials and Methods}

\section{$\mathrm{X}$-ray fluorescence description}

For XRF analyses, each bone was analysed twice: the first analysis examined an unmodified, visibly clean surface (e.g. the unburred surface); the second tested a surface that had been prepared using a silicon carbide abrading tool (e.g. the burred surface). XRF analyses were conducted using a Bruker Tracer III-V handheld spectrometer. This instrument is equipped with a rhodium tube and a Si-PIN detector with a resolution of ca. $170 \mathrm{eV}$ FWHM for $5.9 \mathrm{keV} \mathrm{X}$-rays (at 1000 counts per second) in an area $7 \mathrm{~mm}^{2}$. All analyses were conducted at $40 \mathrm{keV}, 15 \mu \mathrm{A}$ using a $0.127 \mathrm{~mm}$ copper filter in the X-ray path for a 100 second live-time count.

XRF data were then imported into Elva-X Regression (Elvatech LTD, Kiev, Ukraine) for quantification. Peak intensities for $\mathrm{Pb}$ were calculated as ratios to the Compton peak of rhodium, and converted to parts-per-million (ppm) using a quadratic model derived from the analysis of 9 matrix matched standards (see below).

Matrix matched standards were made by 
Table 1. Comparison of data generated by $\mathrm{X}$-ray fluorescence and inductively coupled plasma-time-of-flight-mass spectrometer.

\begin{tabular}{lccc} 
Sample ID & XRF & & $\begin{array}{c}\text { ICP-TOF-NS } \\
(\text { ppm })\end{array}$ \\
\hline 256 & 414.1 & 19.9 & 90.2 \\
$257 \mathrm{a}$ & 49.1 & 45.0 & 20.0 \\
\hline 259 & 180.3 & 94.1 & 99.8 \\
261 & 93.2 & 52.1 & 25.2 \\
\hline 266 & 54.5 & 63.7 & 87.9 \\
267 & 32.8 & 13.4 & 33.5 \\
\hline 273 & 87.7 & 25.5 & 17.9 \\
280 & 21.2 & $<5$ & 12.1 \\
\hline 281 & 11.6 & $<5$ & 8.8 \\
282 & $<5$ & $<5$ & 1.2 \\
\hline 284 & 104.0 & 65.4 & 52.2 \\
287 & 37.6 & 43.0 & 38.7 \\
\hline 288 & 31.2 & 38.0 & 30.1 \\
289 & 10.4 & 12.3 & 11.8 \\
\hline 290 & 64.3 & 120.7 & 79.0 \\
291 & 48.0 & 12.0 & 7.5 \\
\hline 293 & 93.3 & 66.5 & 51.3 \\
295 & 23.1 & 11.7 & 17.5 \\
\hline 296 & 82.3 & 67.4 & 48.9 \\
297 & 13.6 & $<5$ & 5.9 \\
\hline 298 & 31.3 & 17.6 & 13.3 \\
300 & 101.1 & 15.3 & 14.4 \\
\hline 301 & 5.8 & $<5$ & 5.0 \\
\hline 306 & 9.1 & $<.5$ & 20.3 \\
\hline 308 & 48.5 & $<5$ & Burred \\
\hline
\end{tabular}

Sample ID, sample identification number; XRF, X-ray fluorescence; ICP-TOF-MS, inductively coupled plasma-time-of-flight-mass spectrometer. spiking powdered bone meal with ICP-MS Pb solutions of known concentration. The solution was then allowed to evaporate and the resulting powder was mechanically homogenised using an agate mill. Aliquots of the powder were then pressed into pellets. A second aliquot of each standard was analysed by ICP-MS using the methods described above to verify actual concentrations. Observed versus expected values in the bone standards were determined to be in agreement. In total, nine standards were produced with target concentrations of $1,25,50,100,250,500,1000$, 2500 , and $5000 \mathrm{ppm}$.

\section{Inductively coupled plasma-mass spectrometry description}

For analysis by ICP-MS, the exterior surfaces of each bone sample were first prepared using a silicon carbide abrading tool and then powdered using an agate mortar and pestle. Following initial sample preparation, $50 \mathrm{mg}$ of the powdered samples were weighed into trace metal-free $15 \mathrm{~mL}$ polypropylene centrifuge tubes. Samples were digested using $4 \mathrm{~mL}$ concentrated $\mathrm{HNO}_{3}$ and $1 \mathrm{~mL}$ concentrated $\mathrm{H}_{2} \mathrm{O}_{2}$. Tubes containing the bone and acid were sonicated in a water bath at $70^{\circ} \mathrm{C}$ until the bone was fully digested. Quality control samples of NIST SRM 1486 (bone meal) were similarly prepared. A $100 \mathrm{mg}$ aliquot of digestate from each sample was weighed into clean $15 \mathrm{~mL}$ centrifuge tubes. The digestate was then topped off to $10 \mathrm{~g}$ with $2 \% \mathrm{HNO}_{3}$ (Little et al., 2004). Standard solutions and blanks were similarly prepared.

The instrumentation used in this analysis was a GBC Optimass 9500 (GBC Scientific Equipment, Braeside, Australia) inductively coupled plasma-time-of-flight-mass spectrometer (ICP-TOFMS). The digested samples, quality controls, blanks and standards were introduced into the instrument via a peristaltic

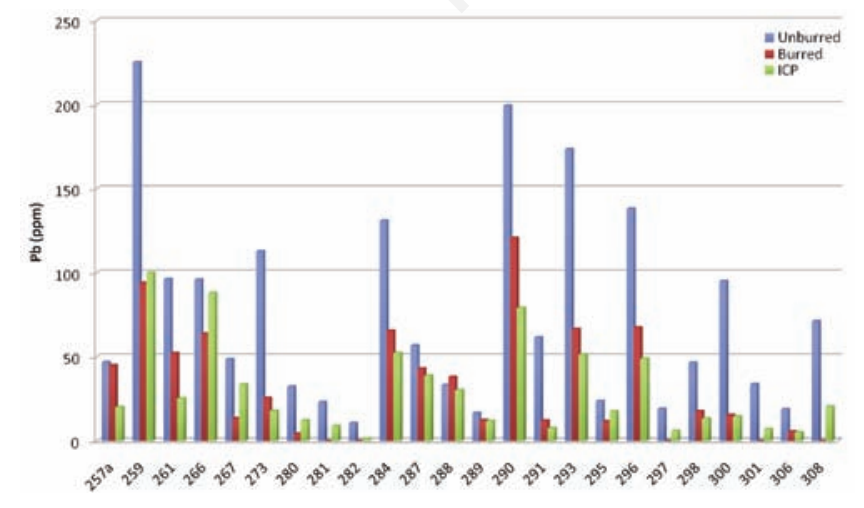

Figure 1. Graph showing the comparison of ppm lead measured by $\mathrm{X}$-ray fluorescence and inductively coupled plasma-time-offlight-mass spectrometer for both burred and unburred bone. Sample $\mathbf{2 5 6}$ is not shown due to the disproportionately high lead content in this sample.

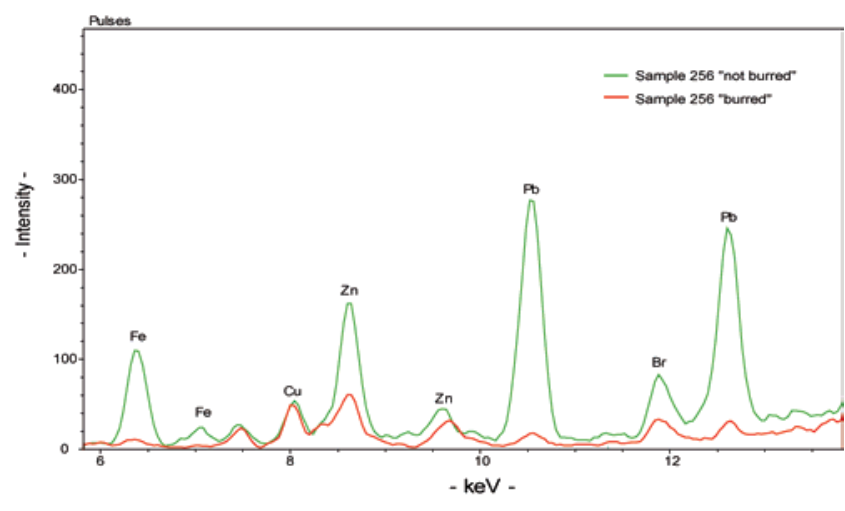

Figure 2. Spectra showing the difference in X-ray fluorescence intensity of lead peaks for burred and unburred bone for sample sample 256. Lead concentrations for the unburred and burred samples are 414 and $20 \mathrm{ppm}$, respectively. 
pump, where argon gas plasma capable of sustaining temperatures between 8000 and 10,000 $\mathrm{K}$ is used to ionise the injected sample. The resulting ions then pass though a three-stage interface (1 sample and 2 skimmer cones) designed to enable the transition of the ions from atmospheric pressure to the vacuum chamber of the ICP-TOF-MS system. A voltage is then applied to push the ions past a Smartgate ${ }^{\mathrm{RT}}$ and through a reflectron before reaching the detector.

\section{Results and Discussion}

Data generated by portable XRF for the unburred bone surfaces demonstrated that $\mathrm{Pb}$ values were on average 2-3 times higher than analyses of the burred bone (Figure 1, Table 1), suggesting that burring the exterior of the bone removes a large amount of diagenetic $\mathrm{Pb}$ from the surface of the bone (Figure 2). However, in six samples (266-267 and 287$290), \mathrm{Pb}$ content of the unburred bone was equal to or higher than the burred samples, suggesting that considerable variability exists in $\mathrm{Pb}$ content across the surface of the bone. Examination of these samples showed these bones to be highly mineralised and extremely difficult to abrade. It is likely that sample preparation methods for mineralised bone needs to be adjusted to remove outside surfaces for a more accurate representation of lifelong $\mathrm{Pb}$ accumulation. Additionally, it is important that researchers mechanically remove the outer layers of bone before attempting to compare XRF data with that obtained by ICP-MS.

Overall, $\mathrm{Pb}$ measured by XRF was notably different from $\mathrm{Pb}$ measured by ICP-TOF-MS in the archaeological bone samples. Data generated by XRF of abraded surfaces were consistent with ICP-TOF-MS data for some samples (Table 1). In general, XRF data generally were inconsistent with ICP-MS data at both high and low $\mathrm{Pb}$ concentrations, likely a result of the heterogeneity inherent in the bone matrix and differences between what is essentially a surface analysis (XRF) and a bulk analysis (ICPMS). Nevertheless, we were able to demonstrate the presence/absence of $\mathrm{Pb}$ in both burred and unburred bone in low, moderate, and high amounts.

\section{Conclusions}

We were unable to use portable XRF to generate data for burred samples that were consistently comparable to ICP-TOF-MS data. Much of this disparity results from several factors including variation in $\mathrm{Pb}$ content across the bone (Grupe, 1988), and differences between the two analytical techniques (XRF is a surface analysis, solution ICP-TOF-MS is a bulk analysis). Although portable XRF is ideally suited for rapid and completely non-destructive analyses, it is clear that surface contamination on the bone is a fundamental issue-one that cannot be overcome without proper sample preparation. However, when used as a preliminary qualitative tool, portable XRF can be useful in the selection of human bone samples for future heavy metal quantification in a laboratory setting.

\section{References}

Aras NK, Yilmaz G, Alkan S, Korkusuz F, 1999. Trace elements in human bone determined by neutron activation analysis. J Radioanal Nucl Ch 239:79-86.

Aufderheide AC, Neiman FD, Wittmers Jr. LE, Rapp G, 1981. Lead in bone II: skeletal-lead content as an indicator of lifetime lead ingestion and the social correlates in an archaeological population. Am J Phys Anthropol 55:285-91.

Aufderheide AC, Wittmers Jr. LE, Rapp Jr. G, Wallgren J, 1988. Anthropological applications of skeletal lead analysis. Am Anthropol 90:931-6.
Bellis DJ, Hetter KM, Jones J, Amarasiriwardena D, Parsons PJ, 2006. Calibration of laser ablation inductively coupled plasma mass spectrometry for quantitative measurements of lead in bone. J Anal Atom Spectrom 21:948-54.

Farnum JF, Glascock MD, Sandford MK, Gerritsen S, 1995. Trace elements in ancient human bone and associated soil using NAA. J Radioanal Nucl Ch 196:26774.

Grupe, G. 1988. Impact of the choice of bone samples on trace element data in excavated human skeletons. J Archaeol Sci 15:123-9.

Hoppin JA, Aro ACA, Williams PL, Hu H, Ryan PB, 1995. Validation of K-XRF bone lead measurement in young adults. Environ Health Persp 103:78-83.

Hume IN, 1969. A guide to artifacts of colonial America. University of Pennsylvania Press, Philadelphia, pp 102-22.

Little NC, Kosakowsky LJ, Speakman RJ, Glascock MD, Lohse JS, 2004. Characterization of Maya pottery by INAA and ICP-MS. J Radioanal Nucl Ch 262:10310.

Neeleman HL, 1992. Human lead exposure. CRC Press, Boca Raton, FL, pp 27-31.

Speakman RJ, Neff H, 2005. The application of laser ablation ICP-MS to the study of archaeological materials: an introduction. In: R.J. Speakman and H. Neff (eds.) Laser ablation ICP-MS in archaeological research. University of New Mexico Press, Albuquerque, NM, pp 1-15.

Speakman RJ, Glascock MD, Tykot RH, Descantes C, Thatcher JJ, Skinner CE, Lienhop KM, 2007. Selected applications of laser ablation inductively coupled plasmamass spectrometry to archaeological research. In: M.D. Glascock, R.J. Speakman, R.S. Popelka-Filcoff (eds.) Archaeological chemistry: analytical methods and archaeological interpretation. American Chemical Society ed., Washington, DC, pp 275-96. 